\title{
Two Types of Gastric Excitatory Responses to Stimulation of the Vagal Trunk in Cats: Efferent and Afferent Responses
}

\author{
Tatsuyuki TSUBOMURA ${ }^{1}$, Kazuyoshi KURAHASHI ${ }^{1,2}$ \\ Toshihiro OKAMOTO' ${ }^{\prime}$ and Motohatsu FUJIWARA ${ }^{1}$ \\ 'Department of Pharmacology. Faculty of Medicine. \\ and ${ }^{2}$ Radioisotope Research: Center, Kyoto University. \\ Kyoto 606. Japan
}

Accepted March 2. 1988

\begin{abstract}
Experiments were performed on cats anesthetized with pentobarbital sodium and gallamine triethiodide. Gastric motility was recorded by a balloon method. The excitatory response to electrical stimulation of the vagal trunk was composed of an initial response during the stimulation period and a late response following stimulation. The maximal excitation of the initial response was elicited by a short pulse duration and that of the late response by a long pulse duration. The initial response was inhibited by treatment with hexamethonium or atropine. The late response was hexamethonium-resistant. This hexamethonium-resistant response was inhibited by atropine, hemicholinium and morphine, and enhanced by physostigmine. Treatment with (D-Pro ${ }^{2}, D$ - $\operatorname{Trp}^{7,9}$ )-substance $P$ did not affect the hexamethonium-resistant response. Treatment with morphine inhibited the late response without affecting the initial response. From these results, it was suggested that the initial excitatory response was probably due to the activation of the parasympathetic cholinergic fibers. The late response might be due to the activation of the vagal afferent cholinergic fibers, since the pharmacalogical nature of the late response was similar to that in the cat with supranodose vagotomy (surviving afferent fibers) in our previous reports.
\end{abstract}

The composition of vagal efferent and afferent fibers in cats is worked out using the conventional degeneration technique and the fibers surviving after chronic supranodose vagotomy are almost entirely sensory with their cell stations in the nodose ganglion (14). Recent electronmicroscopic studies have shown that the composition of afferent fibers in the vagal trunk of cats is more than $90 \%$ of the total fibers (5).

Previous studies in our laboratory have shown that the transmission through the superior cervical ganglion reinnervated by the vagal afferent fibers is inhibited by both nicotinic and muscarinic blocking agents. Neurochemical studies demonstrated that the activities of choline acetyltransferase and cholinesterase in the superior cervical ganglia reinnervated by the vagal afferent fibers were higher than those in the preganglionically denervated ganglion $(6,7)$. These findings suggested that feline vagal afferent fibers are at least in part cholinergic. In cats with chronic supranodose vagotomy (for degeneration of the parasympathetic efferent fibers at the supranodose ganglion level), the features of the afferent response of the stomach to stimulation of the vagal trunk are as follows: to elicit the maximal response. rather long pulse duration is required and the response is hexamethonium-resistant, atropine-sensitive and morphine-sensitive $(8,9)$. It may be possible to elicit such a cholinergic afferent-excitatory response of the stomach by stimulating the intact vagal trunk, which contains parasympathetic efferent and afferent fibers.

The present experiments were undertaken to differentiate the vagal afferent response of the stomach from the parasympathetic efferent 
response in normal cats (without chronic supranodose vagotomy), using short or long pulse stimuli and pharmacological agents.

\section{Materials and Methods}

Twenty-five cats of either sex, weighing 2.5 to $3.5 \mathrm{~kg}$, were used. The animals were deprived of food but had free access to water $24 \mathrm{hr}$ prior to the experiment. Anesthesia was induced with ether and pentobarbital sodium $(10 \mathrm{mg} / \mathrm{kg}$. i.v.), and a tracheal cannula was inserted. The right femoral vein was catheterized and gallamine triethiodide $(20 \mathrm{mg} /$ $\mathrm{ml}$ ) was continuously infused at a constant rate $(1.48 \mathrm{ml} / \mathrm{hr})$. Artificial respiration was maintained by a respirator at a rate of 15 strokes/min with an air volume of $50 \mathrm{ml}$ per stroke. The left femoral vein was catheterized for drug administration. The body temperature of animals was kept at approximately $38^{\circ} \mathrm{C}$ by an electrical pad with a rectum thermister.

Recording the motility of the stomach: Gastric motility was recorded using a rubber balloon connected to a catheter introduced via the esophagus. Intragastric pressure was maintained at a water height of 5 to $10 \mathrm{~cm}$. Changes in intragastric pressure were recorded on a polygraph (San-Ei Instrument Co.. Ltd.) through a pressure transducer. To eliminate involvement of $\alpha$ - and $\beta$-adrenoceptors, phentolamine ( $2 \mathrm{mg} / \mathrm{kg}, \mathrm{i} . \mathrm{v}$ ) and propranolol (1 mg/ $\mathrm{kg}$. i.v.) were administered.

Nerve stimulation: The neck of the animal was opened. Both sides of the vagal trunk were dissected caudal to the nodose ganglion, and the cut ends were ligated. To apply electrical stimulation to the distal trunk of the left vagus, a paraffin (saturated with saline) pool in the cervical part was made by tying skin flaps to metal frames as described by Fujiwara et al. (7). The trunk was stimulated by platinum electrodes and rectangular pulses of various durations, $10 \mathrm{~Hz}$ in frequency, 15 volt in intensity, for $10 \mathrm{sec}$.

Measurement of effects of various agents on the response of the stomach: Effects of various agents on the excitatory response of the stomach were expressed as percent changes. The height of the response before administrations of agents was taken as $100 \%$ (control), and the changes of the height after administrations of various agents were ex- pressed as percent changes to the control.

Drugs: Drugs used were phentolamine mesylate (Regitin: Ciba-Geigy Japan, Ltd., Takarazuka, Japan), propranolol hydrochloride (Inderal: Sumitomo Pharmaceuticals Co., Ltd., Osaka, Japan), hexamethonium bromide (Nakarai Chemicals, Ltd., Kyoto. Japan), atropine sulfate (Wako Pure Chemical Industries, Ltd., Osaka, Japan), physostigmine salicylate (Sigma Chemical Co., St. Louis, MO), hemicholinium-3 hydrate (AIdrich Chemical Company, Inc.. Milwaukee. WI), morphine hydrochloride (Takeda Chemical Industries Co., Osaka, Japan), (D-Pro². $D$-Trp ${ }^{7.9}$ )-substance $P$ (Peptide Institute. Inc.. Osaka. Japan). The drugs were dissolved in saline.

Statistics: Results are presented as means \pm S.E. Statistical significance was calculated by Student's $t$-test for unpaired comparisons.

\section{Results}

Relationship between pulse duration and excitatory response to stimulation of the vagal trunk: As shown in Fig. 1, the pattern of the excitatory response of the stomach

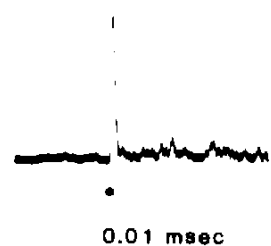

$0.01 \mathrm{msec}$

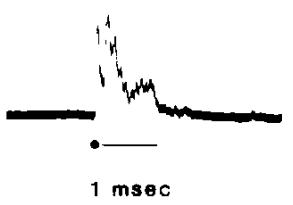

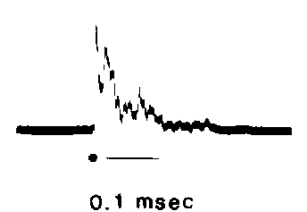

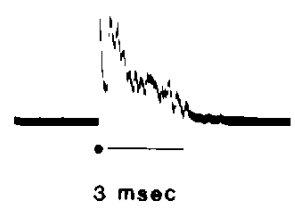

Fig. 1. The pattern of the excitatory response of the feline stomach to various durations of electrical sti:nulation of the vagal trunk with $10 \mathrm{~Hz}$ in frequency, 15 volt in intensity, for $10 \mathrm{ser}$. : the initial excitatory response of the stomach during stimulation. Horizontal bar: the late response following stimulation. Vertical scale: $5 \mathrm{~cm}$ water height. Horizontal scale: $5 \mathrm{~m} ! \mathrm{n}$. 
varied according to the pulse duration of electrical stimulation of the vagal trunk. With a short pulse duration, an initial excitatory response was elicited during stimulation, and after the cessation of stimulation, the tone rapidly returned to the basal level. With a longer pulse duration, such an initial excitatory response was followed by a slowly developing excitatory response after the cessation of stimulation. Thus. the excitatory response of the stomach was divided into two components, an initial response during stimulation of a short pulse duration and a late response following stimulation with a long pulse duration. The relationship between the pulse duration of stimuli and the excitatory response is shown in Fig. 2. The threshold duration for producing an initial excitatory response was less than $0.01 \mathrm{msec}$, and the response showed the tendency to decrease with prolongation of pulse duration of stimuli (Fig. 2A). The threshold for a late excitatory response was about $0.01 \mathrm{msec}$, and the

A

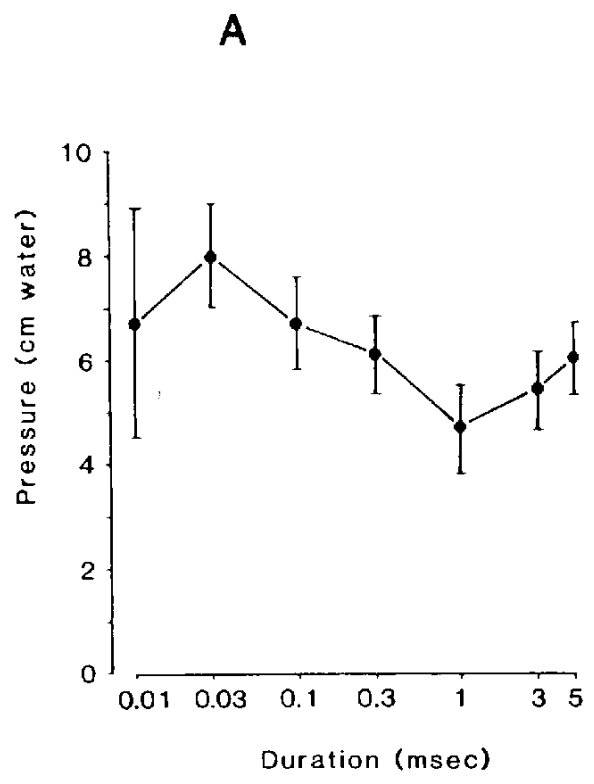

excitatory response was enhanced by increasing pulse duration. The duration to obtain the maximal excitatory response was $1 \mathrm{msec}$ (Fig. 2B), and the relationship between the pulse duration and the response was similar to that in chronic supranodose vagotomized cats with degenerated efferent but surviving afferent fibers $(8,9)$.

Effects of hexamethonium on the initial and late excitatory responses to stimulation of the vagal trunk: The administration of hexamethonium ( 1 to $10 \mathrm{mg} / \mathrm{kg}$, i.v.) inhibited dose-dependently the initial excitatory response of the stomach to electrical stimulation of 0.01 to $5 \mathrm{msec}$ in duration. The inhibition of the response by hexamethonium $(10 \mathrm{mg} / \mathrm{kg}$. i.v.) continued for more than $60 \mathrm{~min}$. Figure 3 shows a representative recording of the effects of hexamethonium on the initial and late excitatory response of the stomach to vagal stimulation of $3 \mathrm{msec}$ in duration. The treatment with hexamethonium $(10 \mathrm{mg} / \mathrm{kg}$, i.v.) inhibited almost completely the initial

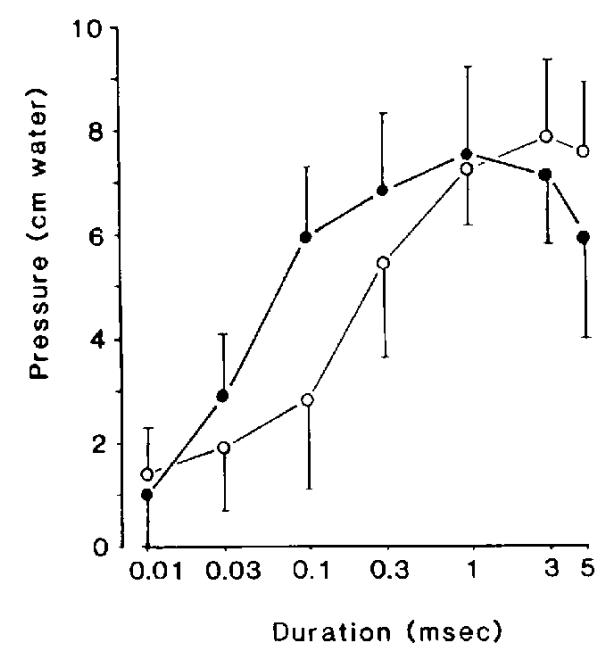

Fig. 2. Relationship between the excitatory response of the stomach and duration of stimulation of the vagal trunk in cats. Electrical stimulation: $10 \mathrm{~Hz}$ in frequency. 0.01 to $5 \mathrm{msec}$ in duration and 15 volt in intensity, for $10 \mathrm{sec}$. A: initial excitatory response of the stomach to stimulation of various pulse durations in nonoperated cats $(n=6)$ and $B$ : late excitatory response of the stomach to stimulation of various pulse durations in nonoperated cats $(n=6)$ (O) and in the supranodose vagotomized cats $(n=5)(O)$. The results in the supranodose vagotomized cat are cited from our previous report (Tsubomura et a!., 1987). Symbols with bars indicate mean values with S.E. 


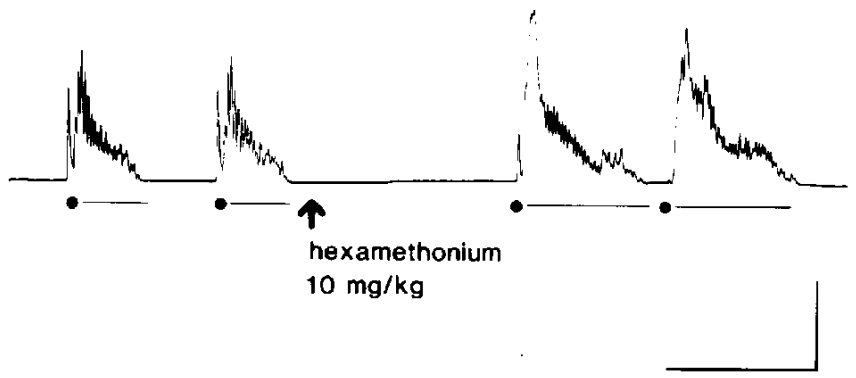

Fig. 3. Effects of hexamethonium $(10 \mathrm{mg} / \mathrm{kg}, 1 . \mathrm{v}$ ) on the initial and late excitatory responses of the stomach to electrical stimulation of the vagal trunk $(10 \mathrm{~Hz}$ in frequency. 3 msec in duration and 15 volt in intensity for $10 \mathrm{sec}$ ). : the initial excitatory response of the stomach. Harizontal bar: the late excitatory response of the stomach. Vertical scale: $5 \mathrm{~cm}$ water height. Horizontal scale: $5 \mathrm{~min}$.

Table 1. Effect of atropine on the excitatory response of the stomach to electrical stimulation of the vagal trunk in cats

\begin{tabular}{cc}
$\begin{array}{c}\text { Atropine } \\
(\mu \mathrm{kg} / \mathrm{kg} . \mathrm{i} . \mathrm{v})\end{array}$ & $\%$ inhibition \\
3 & $9 \pm 5(\mathrm{n}=3)$ \\
10 & $47 \pm 5(n=4)$ \\
30 & $92 \pm 5(n=3)$ \\
\hline
\end{tabular}

Effect of atropine on the response is expressed as percent inhibition, compared with the response before atropine in ection. The values indicate the meantS.E. of the percent inhibition by atropine. The number of experiments is indicated in parentheses.

excitatory response, but rather enhanced the late excitatory response. The mean enhancement was approximately $45 \%(n=4)$. Thus, there were two types of excitatory responses of the stomach to vagal stimulation: hexamethonium-sensitive and hexamethoniumresistant. The administration of atropine (3, 10 and $30 \mu \mathrm{g} / \mathrm{kg}$. i.v.) inhibited both responses dose-dependently, and these were almost completely abolished by $30 \mu \mathrm{g} / \mathrm{kg}$. In the following experiments, the nature of the hexamethonium-resistant response produced by a long pulse duration ( $3 \mathrm{msec}$ ) was analyzed.

Effects of atropine, physostigmine, hemicholinium, morphine and (D-Pro ${ }^{2}$, D-Trp ${ }^{7,9}$ )substance $P$ on the hexamethonium-resistant response to vagal stimulation with a long pulse duration: Twenty min after the first administration of hexamethonium (10 mg/ $\mathrm{kg}, \mathrm{i} . v$.$) , the same agent was again adminis-$ tered to completely block the nicotinic receptors. Then, the effects of the following agents on the hexamethonium-resistant re- sponse were investigated. The administration of atropine $(3,10$ and $30 \mu \mathrm{g} / \mathrm{kg}, \mathrm{i} . \mathrm{v}$.) caused a dose-dependent inhibition of the response (Fig. 4A and Table 1), and the inhibition was not recovered within $120 \mathrm{~min}$. On the other hand. treatment by physostigmine $(300 \mu \mathrm{g} /$ $\mathrm{kg}$, i.v.) enhanced the response by $33 \%$ (mean value, $n=4$ ) (Fig. 4B). As shown in Fig. 4C. the administration of hemicholinium (10 mg/ $\mathrm{kg}$, i.v.) almost completely inhibited the excitatory response in 4 cats. The administration of morphine $(5 \mathrm{mg} / \mathrm{kg}$, i.v.) attenuated the response by about $51 \%$ of the original response $(n=3)$ (Fig. 4D). In three cats, the substance $P$ antagonist (D-Pro ${ }^{2}, D-\operatorname{Trp}^{7,9}$ )substance $P(250$ and $500 \mu \mathrm{g} / \mathrm{kg}$, i.v. ) did not affect the excitatory response at all.

Effects of morphine on the initial and late excitatory responses to electrical stimulation of the vagal trunk: Effects of morphine on gastric excitatory responses were analyzed without administration of hexamethonium. The administration of morphine in doses below $100 \mu \mathrm{g} / \mathrm{kg}$, i.v. did not affect either the 
initial or the late response to vagal stimulation with 3 msec pulse duration. However, morphine in doses of 1.3 and $5 \mathrm{mg} / \mathrm{kg}$ inhibited dose-dependently the late excitatory response without affecting the initial response, and the extents of the inhibition (mean values, $n=4$ ) were $25 \%, 38 \%$ and $56 \%$ respectively, as compared with the response before adminis-
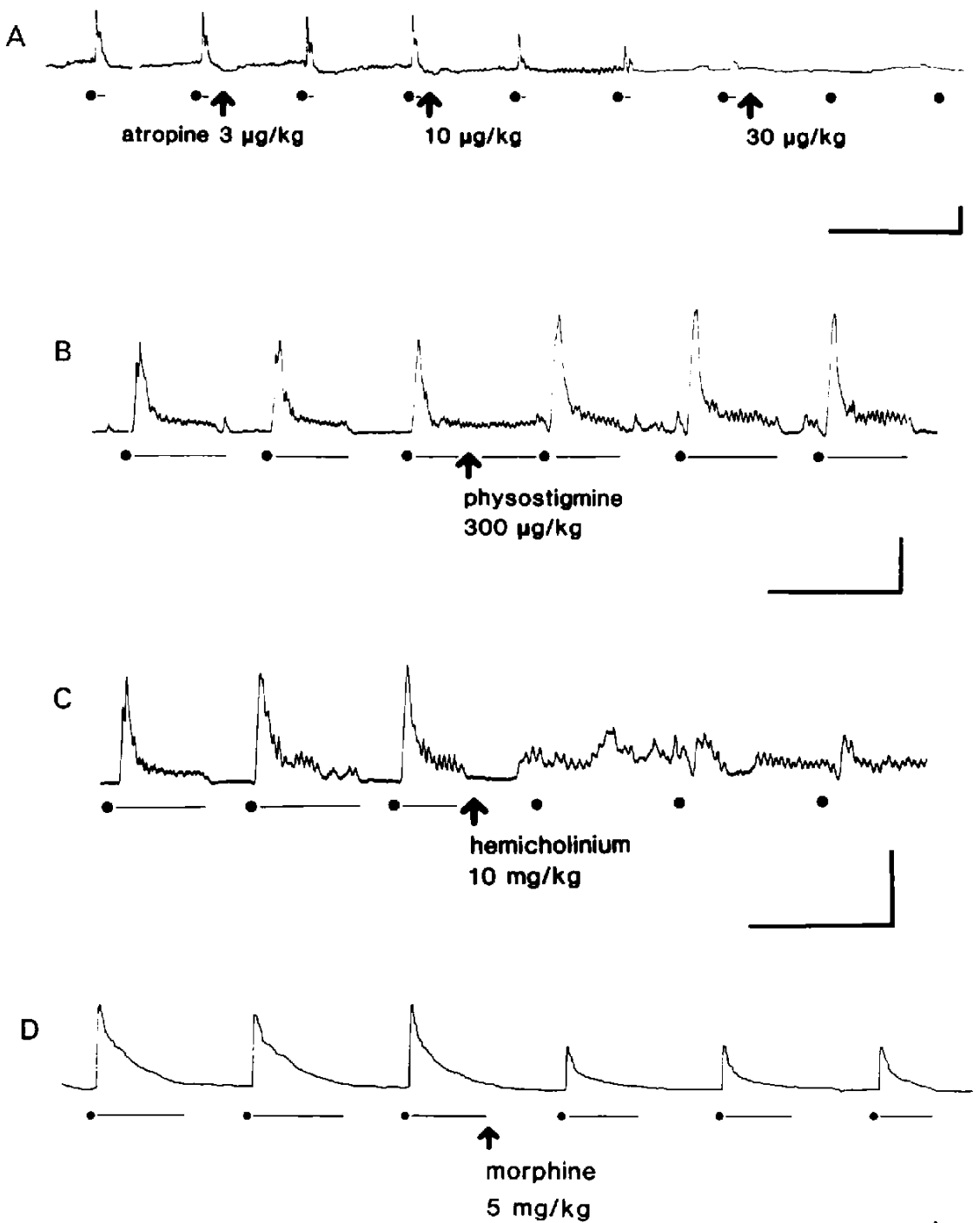

Fig. 4. Effects of atropine, physostigmine, hemicholinium and morphine on the hexamethonium. resistant, late excitatory response of the stomach to stimulation of the vagal trunk (10 $\mathrm{Hz}$ in frequency. $3 \mathrm{msec}$ in duration and 15 volt in intensity for $10 \mathrm{sec})$. $:$ the initial excitatory response of the stomach. Horizontal bar: the late excitatory response of the stomach. A: effects of atropine $(3,10$ and $30 \mu \mathrm{g} / \mathrm{kg}$. i.v.). Vertical scale: $4 \mathrm{~cm}$ water height. Horizontal scale: $5 \mathrm{~min}$. B: effects of physostigmine (300 $\mu \mathrm{g} /$ kg, i.v.). Vertical scale: $4 \mathrm{~cm}$ water height. Horizontal scale: $5 \mathrm{~min}$. C: effects of hemicholinium (10 $\mathrm{mg} / \mathrm{kg}$. i.v.). Vertica! scale: $5 \mathrm{~cm}$ water height. Horizontal scale: $5 \mathrm{~min}$. D: effects of morphine $(5$ $\mathrm{mg} / \mathrm{kg}$, i.v.). Vertical scale: $5 \mathrm{~cm}$ water height. Horizontal scale: $5 \mathrm{~min}$. 
A before morphine

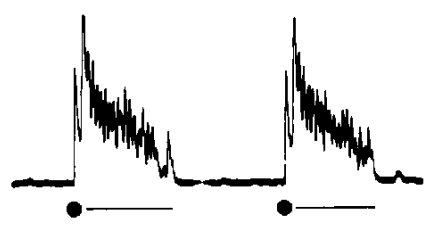

B after morphine

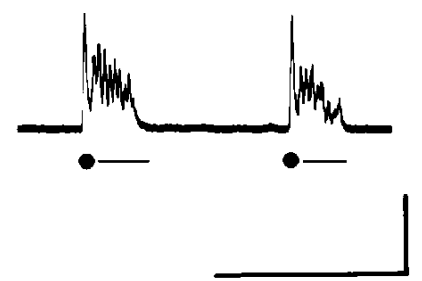

Fig. 5. Effects of morphine $(5 \mathrm{mg} / \mathrm{kg}, \mathrm{i} . \mathrm{v}$.) on the initial and late excitatory responses of the stomach to stimulation of the vagal trunk $(10 \mathrm{~Hz}$ frequency, $3 \mathrm{msec}$ in duration and 15 volt in intensity, for $10 \mathrm{sec})$.

- : the initial excitatory response during stimulation. Horizontal bar: the late excitatory response after the stimulation. Vertical scale: $4 \mathrm{~cm}$ water height. Horizontal scale: $5 \mathrm{~min}$.

tration of morphine (Fig. 5).

\section{Discussion}

The present study demonstrated that the excitatory responses of the stomach to vagal stimulation in cats is composed of two types of responses: the initial one during stimulation by a short or long pulse duration stimulus is hexamethonium- and atropine-sensitive but morphine-resistant, while the late one, which occurs after the stimulation of the vagal trunk by a stimulus of longer pulse duration. is hexamethonium-resistant but atropineand morphine-sensitive.

The only response seen in cats with chronic supranodose vagotomy was the late excitatory response (9), and the relationship between the pulse duration and the response was similar to that seen in the late excitatory response in normal cats. The initial response to either short or long pulse duration was hexamethonium- and atropine-sensitive, and it was probably due to activation of parasympathetic cholinergic nerves. On the other hand, the late excitatory response to a stimulus of longer pulse duration was hexamethonium-resistant, inhibited by atropine and hemicholinium, and enhanced by physostigmine. These two types of responses were clearly differentiated by the pulse duration of stimuli and administration of hexamethonium. The observation of hexamethonium-resistant excitatory responses to vagal stimulation with longer pulse duration was compatible with our previous observation that stimulation of the vagal trunk with chronic supranodose vagotomy (degeneration of parasympathetic efferent fibers) produced only a late gastric response to longer pulse duration $(8,9)$. The present findings were in agreement with those of Delbro et al. $(10,11)$ who reported hexamethonium-resistant and atropine-sensitive responses of the stomach in response to electrical stimulation of the intact vagal trunk in normal cats. There were however a few clear differences between the present findings and those of De!bro et al. (10-12): 1) They did not report any late excitatory response of the stomach at long pulse duration before administration of hexamethonium in their experimental method, but we observed both excitatory responses (initial and late) at long pulse duration without administration of hexamethonium; 2) A substance $P$ antagonist was effective in their experimental method. but was not effective in ours. Although there are no clear explanations for these differences. they are likely due to the different recording methods (constant volume in our experimental method and constant pressure in Delbro's method). This difference may affect the pattern of response and the effectiveness of the substance $P$ antagonist. Indeed, the response varied according to our experimental method. Under the present experimental method (constant volume to record the response), the inhibitory response of the stomach to stimulation of the vagal trunk was not observed. In contrast with this method. using the volume recording system, distinct excitatory responses were not always seen but this method clearly recorded the inhibitory 
response to vagal stimulation (13).

The effect of atropine, physostigmine and hemicholinium on the hexamethonium-resistant excitatory response in the present experiments was in agreement with our previous findings in chronic supranodose vagotomized cats $(8,9)$. Thus, the late response to a longer pulse duration could be elicited by activation of the cholinergic neurons in between the nodose ganglion and the gastric wall, and the fibers involved might be vagal afferents. Another interesting finding was the enhancement of the late excitatory response by hexamethonium, as was also seen in the cat with supranodose vagotomy. At present, there is no clear explanation for this enhancement. Some vagal afferent fibers may have connections with inhibitory neurons in the stomach and this neuron activity may be blocked by hexamethonium. There was another clear difference between the initial and the late excitatory response of the stomach. Morphine had no effect on the initial response but inhibited the late response as shown in a preliminary report (14). This indicates that the nature of the fibers that elicit each response is pharmacologically different. Indeed, in early studies on the effect of morphine in guinea-pig intestine in vitro, Schaumann $(15,16)$ suggested that morphine inhibited the release of acetylcholine from nerve fibers or nerve endings of an unknown nature. There might be different types of cholinergic fibers in terms of susceptibility to morphine. We have reported that the vagal afferent fibers in the cat are, at least in part, cholinergic $(6,7)$. Moreover, there are definitely detectable amounts of $\mathrm{ACh}$ in nodose ganglion following chronic supranodose vagotomy in the cat (9).

The present experiments demonstrated that in normal cat, the late excitatory response of the stomach (vagal afferent response) and the initial excitatory response of the stomach (vagal efferent response) could be differentiated by using stimuli of different pulse duration and by the administration of hexamethonium or morphine. The pharmacological natures of the late excitatory response of the stomach of the normal cat were similar to those of the late excitatory response in the cat with chronic supranodose vagotomy.
Acknowledgment: This study was supported in part by a Grant-in-Aid from the Smoking Research Foundation, Japan.

\section{References}

1 Daly, M. and Evans, D.H.L.: Functional and histological changes in the vagus nerve of the cat after degenerative section at various levels. J. Physiol. (Lond.) 120, 579-595 (1953)

2 Evans, D.H.L. and Murray, J.G.: Histological and function studies on the fibre composition of the vagus nerve of the rabbit. J. Anat. $88,320-337$ (1954)

3 Agostoni, E., Chinnock, J.E., De Burgh Daly, M. and Murray, J.G.: Functional and histological studies of the vagus nerve and its branches to the heart, lungs and abdominal viscera in the cat. J. Physiol. (Lond.) 135, 182-205 (1957)

4 Paintal, A.S.: Vagal afferent fibers. Ergeb. Physiol. 52, 75-148 (1963)

5 Mei, N., Condamin, M. and Boyer, A.: The composition of the vagus nerve of the cat. Cell Tissue Res. 209, 423-431 (1980)

6 Fujiwara, M. and Kurahashi, K.: Cholinergic nature of the primary afferer,t vagus synapsed in cross anastomosed superior cervical ganglia. Life Sci. 19, 1175-1180 (1976)

7 Fujiwara, M., Kurahashi, K., Mizuno, N. and Nakamura, Y.: Involvement of nicotinic and muscarinic receptors in synaptic transmission in cat superior cervical gangtion reinnervated by vagal primary afferent axons. J. Pharmacol. Exp. Ther. 205, 77-90 (1978)

8 Kurahashi, K., Fujiwara, M. and Taniguchi, T.: Cholinergic excitatory response of stomach to stimulation of the vagal trunk in cats with chronic supranodose vagotomy. IRCS Med. Sci. 11, 62 (1983)

9 Tsubomura, T., Okamoto, T., Kurahashi, K. and Fujiwara, M.: Gastric excitation by stimulation of the vagat trunk after chronic supranodose vagotomy in cats. J. Pharmacol. Exp. Ther. 241, 650-654 (1987)

10 Delbro, D., Fändriks, L., Lisander, B. and Andersson, S.A.: Hexamethonium-resistant, atropine-sensitive vagal excitation of the feline stomach-activation of an unknown fibre system. Acta Physiol. Scand. 112, 493-494 (1981)

11 Delbro, D., Fändriks, L., Lisander, B. and Andersson, S.A.: Gastric atropine-sensitive excitation by peripheral vagal stimulation after hexamethonium. Antidromic activation of afferents? Acta Physiol. Scand. 114, 433-440 (1982)

12 Delbro, D., Fändriks, L., Rosell, S. and Folkers, 
K.: Inhibition of antidromically induced stimulation of gastric motility by substance $P$ receptor blockade. Acta Physiol. Scand. 118, 309-316 (1983)

13 Martinson, J.: The effect of graded vagal stimulation on gastric motility, secretion and blood flow in the cat. Acta Physiol. Scand. 65, 300-309 (1965)

14 Okamoto, T., Kurahashi, K., Tsubomura, T. and Fujiwara, M.: Effects of morphine on hexamethonium-sensitive and -resistant excitatory response of stomach to stimulation of vagal trunk in cats. Life Sci. 39, 147-153 (1986)

15 Schaumann, W.: influence of atropine and morphine on the liberation of acetylcholine from the guinea-pig's intestine. Nature 178, 11211122 (1956)

16 Schaumann, $W$ : Inhibition by morphine of the release of acetylcholine from the intestine of the guinea-pig. Br. J. Pharmacol. 12, 115-118 (1957) 